\title{
Supporting Information for Response Characteristics of a Reversible Electrochemical Sensor for the Polyion Protamine
}

\author{
Alexey Shvarev and Eric Bakker* \\ Department of Chemistry and Biochemistry, Auburn University, Auburn, Alabama 36849
}

Response of membrane containing tetradodecylammonium tetrakis(4-chlorophenyl)borate (ETH 500) to heparin and protamine. Fig. S1A illustrates potential of a membrane containing $10 \%$ wt of ETH 500 as a function of the applied current in $0.01 \mathrm{M} \mathrm{Na}_{2} \mathrm{SO}_{4}$. solution.
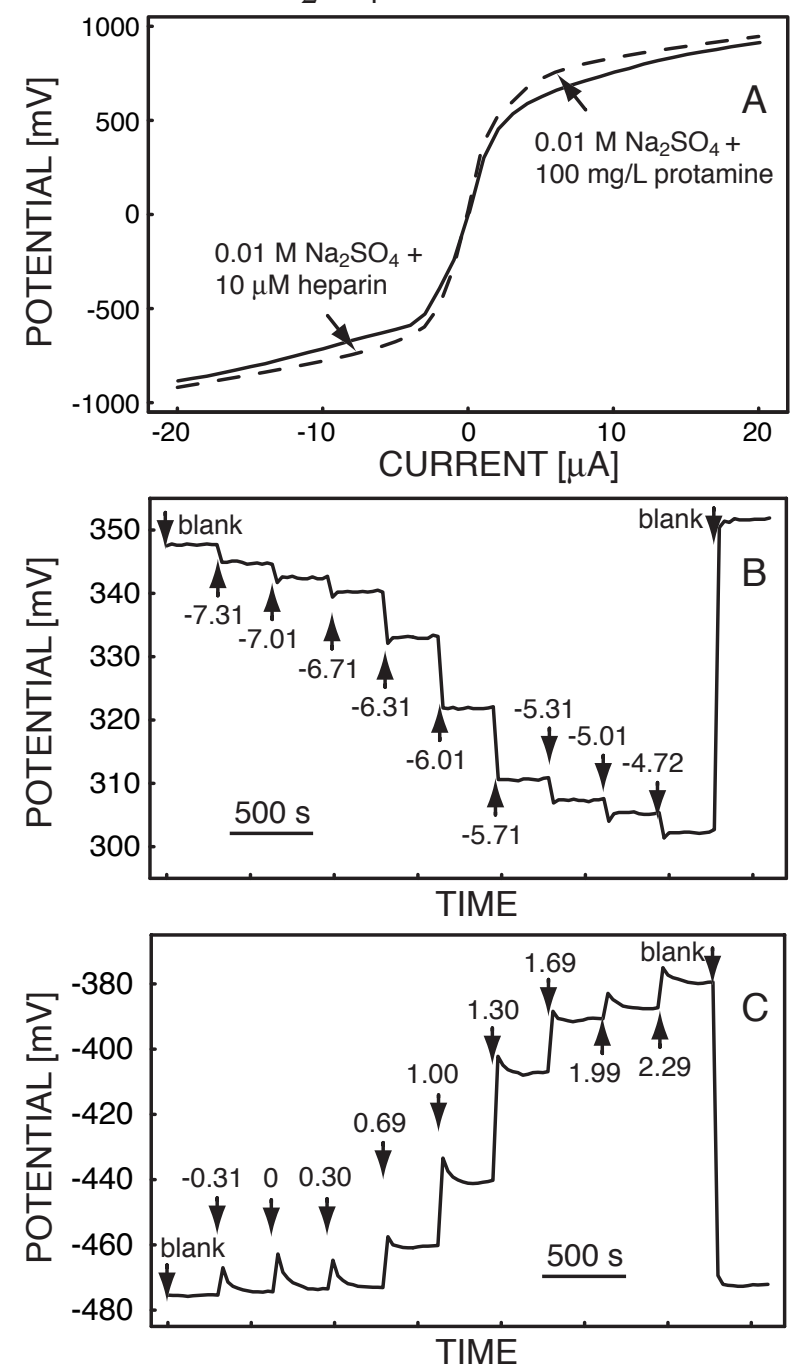

Figure S1 (A) Normal pulse chronopotentiograms for a PVC-NPOE membrane containing $10 \%$ wt. of ETH 500. Solid line represents response in a blank $0.01 \mathrm{M} \mathrm{Na} \mathrm{SO}_{4}$ solution (1 $\mathrm{mM}$ TRIS pH 7.40). Dashed line corresponds to the two separate experiments when heparin (10 mM) and protamine (100 $\left.\mathrm{mg} \mathrm{L}^{-1}\right)$ were added to the blank solution. Response for heparin (B) at an anodic current of $+1 \mu A$ and protamine $(C)$ at a cathodic current of $-2 \mu \mathrm{A}$. The numbers above the plots represent $\log \mathrm{cHep}(\mathrm{M})$ and $\log$ cProtamine $\left(m g L^{-1}\right)$ respectively.

The dotted line corresponds to the measurement in the blank solution while the solid line represents two separate experiments when $10 \mathrm{mM}$ of heparin or $100 \mathrm{mg} \mathrm{L}^{-1}$ of protamine were added to the solution. The resulting potential decreases in the presence of protamine if a cathodic current pulse is applied across the membrane. In the anodic region the resulting potential increases in the presence of heparin. Fig. S1B illustrates the time dependent response for the heparin calibration when $1 \mu \mathrm{A}$ anodic current pulses were applied.
Analogous time-trace response for protamine at a cathodic current of $2 \mu \mathrm{A}$ is shown in Fig. S1C. The potentials, monitored over several minutes for each calibration step were stable. The standard deviation did not exceed $0.8 \mathrm{mV}$. This indicates the absence of spontaneous polyion extraction and suggests that the membrane surface is fully renewed after each extraction pulse. This experiment demonstrates that both polycations and polyanions could, in principle, be determined in separate solutions with the same chronopotentiometric sensor, merely by changing the sign of the applied current.

Effect of the $\mathrm{pH}$ on the protamine sensor response. The influense of the sample $\mathrm{pH}$ on the DNNS-TDDA based protamine sensor response is shown in Fig. S2. The Bottom data in Fig. S2 were obtained at the cathodic current of $-2 \mu \mathrm{A}$. Upper data are the potential readings in the presence of 25 $\mathrm{mg} / \mathrm{L}$ protamine.

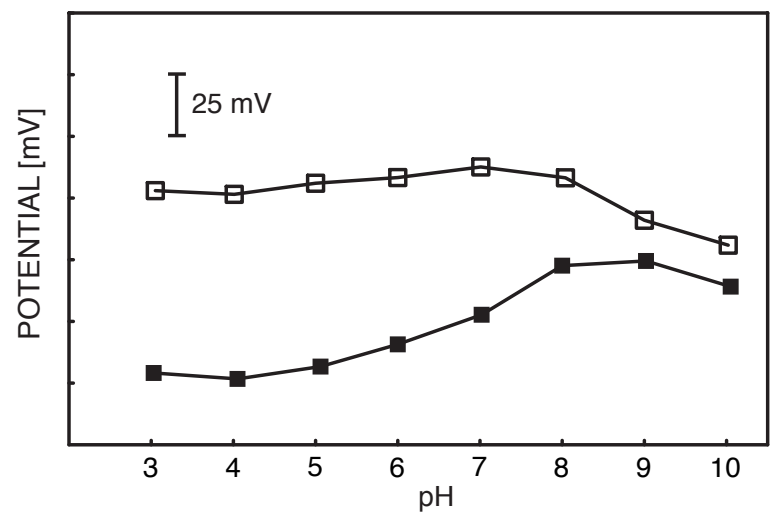

Figure S2. Effect of the pH on a protamine sensor response at a cathodic current of $2 \mu \mathrm{A}$ in $0.1 \mathrm{M} \mathrm{NaCl}$ solution (10 mM TRIS $\mathrm{pH} 7.40$ ).

Lowe curve represents potentials measured in blank solution. Potentials on the upper curve are measured in presence of $25 \mathrm{mg} \mathrm{L}^{-1}$ of protamine.

In the acidic $\mathrm{pH}$ range the sensor response did not depend of the sample $\mathrm{pH}$. Higher $\mathrm{pH}$ reduced the observed potential difference, but the response at $\mathrm{pH} 7.4$ is sufficiently large for a practical application in physiological samples.

Long term stability of the protamine sensor potential in $0.1 \mathrm{M}$ $\mathrm{NaCl}$ solution. In a separate experiment the sensor was placed in $0.1 \mathrm{M} \mathrm{NaCl}(\mathrm{pH} \mathrm{7.40)}$ ) and $10 \mathrm{mg} / \mathrm{L}$ of protamine. The current pulse was applied every minute. Fig. S3 shows the recorded potential as a function of time during $3 \mathrm{~h}$. The total potential change did not exceed $2 \mathrm{mV}$.

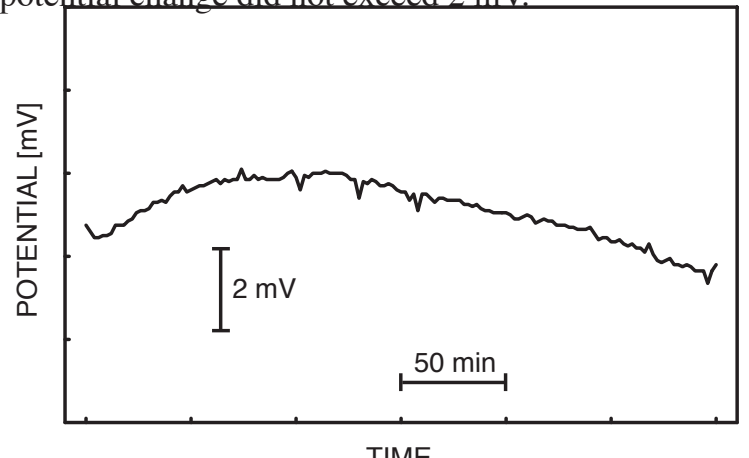

Figure S3. Long term stability of the protamine sensor potential at a cathodic current of $2 \mu \mathrm{A}$ in $0.1 \mathrm{M} \mathrm{NaCl}$ solution (10 mM TRIS $\mathrm{pH} 7.40$ ). 